\title{
Cardiothoracic
}

Transplantation

\section{Brain death leads to abnormal contractile properties of the human donor right ventricle}

Serban C. Stoica, MD, ${ }^{a}$ Duwarakan K. Satchithananda, MRCP, ${ }^{a}$ Paul A. White, PhD, ${ }^{a}$ Linda Sharples, PhD, Jayan Parameshwar, FRCP, ${ }^{a}$ Andrew N. Redington, FRCP, ${ }^{\mathrm{b}}$ and Stephen R. Large, FRCS $^{\mathrm{a}}$

See related editorial on page 10 .
Objectives: Experimental and clinical data suggest that brain death predominantly affects the right ventricle. We aimed to investigate right ventricle function after brain death and during clinical transplantation with load-independent methods.

Methods: Patients with and without brain death were enrolled. A total of 33 consecutive heart donors (5 live, "domino" donors) and 10 patients undergoing coronary surgery (coronary artery bypass graft controls) were studied with pressurevolume loops in the right ventricle. Contractile reserve was measured with dopamine stimulation.

Results: Brain-dead donors had a higher mean cardiac index than coronary artery bypass graft controls (3.3 vs $2.8 \mathrm{~L} / \mathrm{min} / \mathrm{m}^{2}$ ), but impaired load-independent indices. Despite increased right ventricle stroke volume, the ejection fraction and slope of the end-systolic pressure-volume relationship were significantly reduced in brain-dead donors compared with controls. Diastolic abnormalities were also manifest as increased end-diastolic volume index and prolonged Tau $(P<.05)$. Dopamine improved cardiac output, but without influencing end-systolic pressure-volume relationship, or Tau, and at the expense of further increased right ventricle enddiastolic volume. Before explantation, a significantly higher diastolic volume was also seen in hearts that developed postoperative dysfunction compared with organs without this complication (114.4 vs $\left.77.2 \mathrm{~mL} / \mathrm{m}^{2}, P=.02\right)$.

Conclusions: Brain death leads to right ventricle dysfunction, which may go undetected with conventional techniques. Right ventricle dilatation could represent an early marker of failure. Refinement of selection criteria to include load-independent indices of performance may be desirable to help expand the donor pool.

$\mathrm{H}$ eart transplantation faces an increasing imbalance between donor supply and demand. One way of addressing this would be to minimize the number of donor hearts rejected; however, the criteria for donor selection remain imperfect. Despite careful clinical evaluation, there is a significant incidence of early dysfunction, and, de facto, it is not known how many hearts, rejected by conventional criteria, may have been suitable for transplantation. Donor organ performance is, experimentally ${ }^{1}$ and clinically, ${ }^{2}$ a main factor influencing outcome. Indeed, donor organ failure, commonly isolated right ventricular (RV) dysfunction, remains the leading cause of early mortality and morbidity. ${ }^{3}$ 


\section{Abbreviations and Acronyms \\ $\mathrm{CABG}=$ coronary artery bypass graft \\ EDPVR = end-diastolic pressure-volume relationship \\ EDVI = end-diastolic volume index \\ ESPVR $=$ end-systolic pressure-volume relationship \\ $\mathrm{RV} \quad=$ right ventricle}

The complex hemodynamic milieu in the donor and imprecise methods of evaluation confound accurate assessment of donor heart function. We have advocated the use of the pulmonary catheter for donor resuscitation, ${ }^{2}$ currently incorporated in the recommended algorithm of donor management that includes echocardiography. ${ }^{4}$ However, ventricular parameters obtained by thermodilution or echocardiography are load-dependent, and because of its geometry, the RV is even more difficult to assess by conventional echocardiography than the left ventricle. ${ }^{5}$ Furthermore, the relationship between load and intrinsic contractility is complex, and this interaction is particularly difficult to evaluate in the RV. Major changes in both contractility and load do occur, and there is ample evidence that the RV is predominantly affected. ${ }^{6-9}$ Hours after brain death there is a decrease in pulmonary vascular resistance and an increase in pulmonary blood flow, predisposing to "neurogenic" edema. ${ }^{6}$ Simultaneously, the preload recruitable stroke work decreases in both ventricles. ${ }^{7}$ Others argued that the ventricular dysfunction seen in the brain-dead donor is partly adaptive and that its adverse effects can be reduced by judicious control of loading conditions. 8,9

Ventricular pressure-volume loop measurement by conductance catheter technology is relatively load-independent and represents the gold standard for contractile evaluation. Understanding how the RV adapts after brain death and to what extent the adverse changes are compensatory would help in donor selection and, perhaps, improve donor-recipient physiologic matching. We designed a study aimed to measure load-independent RV systolic and diastolic function in brain-dead, optimized human donors in comparison with domino (live) donors and nontransplant patients undergoing coronary surgery (coronary artery bypass graft [CABG] controls). In limited subgroup analyses we also compared usable and unused hearts, according to current Swan-Ganz catheter selection criteria, and donor hearts with and without subsequent early dysfunction in the recipient.

\section{Methods \\ Donors and Coronary Artery Bypass Graft Comparison Group}

The project was approved by the local research ethics committee. Forty-three patients had RV conductance catheter studies (Figure 1). There were 33 consecutive cardiac donors ( 5 domino, cystic fibrosis recipients of heart-lung transplantation) and 10 consecutive

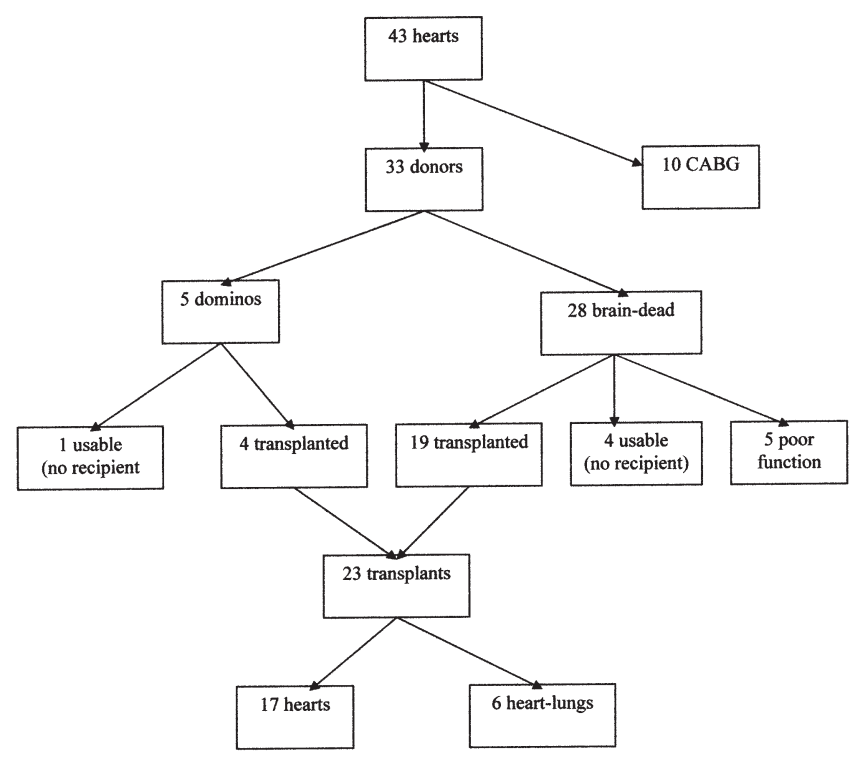

Figure 1. The patients enrolled in the study.

consenting patients who underwent CABG (Figure 1). The latter were all male and had elective coronary revascularization for stable angina and triple vessel coronary artery disease with angiographically normal left ventricular function and no clinical evidence of congestive cardiac failure. Intraoperative RV functional assessment was carried out under similar conditions as in the donor setting, with the pericardium open and at normothermia. All donors were optimized according to our institutional protocol using a pulmonary artery catheter and hormonal infusions. ${ }^{2}$ The donor heart was accepted using standard criteria (the absence of structural or ischemic heart disease, significant ventricular hypertrophy, or ventricular dysfunction). As a guide for the procurement team, therapeutic targets were mean arterial pressure greater than $60 \mathrm{~mm}$ $\mathrm{Hg}$, right atrial and pulmonary capillary wedge pressure less than $12 \mathrm{~mm} \mathrm{Hg}$, left ventricular stroke work index greater than $15 \mathrm{~g} / \mathrm{m}^{2}$, and 1 inotrope only equivalent to less than $5 \mu \mathrm{g} / \mathrm{kg} / \mathrm{min}$ of dopamine. Five donor hearts were not used on grounds of poor function but in the absence of palpable coronary artery disease. At the end of the resuscitation process these 5 organs were performing poorly on visual assessment and required high doses of inotropes. Five other hearts were functionally usable, but a suitable recipient was not identified at the time. Cardioplegic arrest was performed with St Thomas no. 1 solution, and the donor hearts were preserved in normal saline.

\section{Recipients}

Twenty-three transplants resulted (17 hearts and 6 heart-lungs). Indications for heart transplantation were valvular disease (1), dilated cardiomyopathy (6), and ischemic (10) cardiomyopathy. Of the heart-lung recipients, 4 had pulmonary hypertension ( 2 primary and 2 secondary), 1 had cystic fibrosis, and 1 had congenital disease. The mean (standard deviation) age was 60.0 (10.1) years for patients who underwent CABG, 39.2 (12.9) years for braindead donors, and 22.8 (7.0) years for domino donors. Mean (stan- 
TABLE 1. Cardiac parameters at baseline for all patients and usable brain-dead donors $(n=21)$ before and after dopamine stimulation

\begin{tabular}{|c|c|c|c|c|c|c|c|c|}
\hline & Domino $(n=5)$ & Brain-dead $(\mathrm{n}=23)$ & CABG $(n=10)$ & $P^{*}$ (ANOVA) & $P \boldsymbol{P}$ & $\begin{array}{c}\text { Before dopamine } \\
\text { stimulation }(n=21) \neq\end{array}$ & $\begin{array}{c}\text { After dopamine } \\
\text { stimulation }(n=21) \neq\end{array}$ & $P$ \\
\hline HR & $108(8)$ & 95 (14) & $68(11)$ & $<.001$ & $<.001$ & 94 (12) & $105(7)$ & .001 \\
\hline $\mathrm{Cl}$ & $3.8(1.0)$ & $3.3(0.6)$ & $2.8(2.5)$ & .40 & .72 & $3.3(0.6)$ & $4.4(1.1)$ & $<.001$ \\
\hline $\mathrm{EF}$ & $40.4(11.7)$ & $42.2(11.4)$ & $53.2(12.8)$ & .04 & .04 & $40.1(9.3)$ & $42.3(14.5)$ & .39 \\
\hline EDVI & $87.4(21.1)$ & $89.6(36)$ & $55.9(22.0)$ & .02 & .02 & $94.8(35.5)$ & $117.6(47)$ & .001 \\
\hline SVI & $35.5(11.9)$ & $34.8(6.9)$ & $28.9(7.4)$ & .13 & .08 & $35.6(6.8)$ & $45.5(10.4)$ & $<.001$ \\
\hline PVR & 181 (17.3) & $87.6(26.8)$ & - & $<.001$ & - & $87.6(26.6)$ & $86.8(32.9)$ & .93 \\
\hline ESPVR & $0.37(0.15)$ & $0.29(0.13)$ & $0.46(0.23)$ & .03 & .02 & $0.30(0.14)$ & $0.31(0.13)$ & .78 \\
\hline EDPVR & $0.034(0.02)$ & $0.078(0.065)$ & $0.053(0.02)$ & .17 & .62 & $0.078(0.082)$ & $0.072(0.067)$ & .77 \\
\hline $\mathrm{dp} / \mathrm{dt}_{\max }$ & $345(28)$ & $290(89)$ & $223(53)$ & .01 & .08 & $290(89)$ & $475(246)$ & $<.001$ \\
\hline $\mathrm{dp} / \mathrm{dt}_{\min } \S$ & $306(64)$ & $195(148)$ & $110(17)$ & .01 & .17 & 195 (148) & 258 (135) & $<.001$ \\
\hline PRSWI & $9.1(4.1)$ & $7.4(3.1)$ & $7.1(1.9)$ & .43 & .82 & $7.7(3.3)$ & $10.6(3.9)$ & .008 \\
\hline Tau & $31.4(7.1)$ & $58.8(27.6)$ & $87.5(26.8)$ & .004 & .06 & $53.3(27.9)$ & $55.1(22.1)$ & .73 \\
\hline
\end{tabular}

Data shown as mean (standard deviation). *Comparison between all 3 groups (ANOVA). †Comparison between brain-dead donors and CABG, after Bonferroni correction. \$Dopamine stress protocol was not performed in 2 brain-dead donors, thus, $\mathrm{n}=21$. $\S$ Shown as absolute (positive) values. ANOVA, Analysis of variance; $H R$, heart rate (beats $/ \mathrm{min}) ; C l$, cardiac index $\left(\mathrm{L} / \mathrm{min} / \mathrm{m}^{2}\right) ; E F$, ejection fraction (\%); $E D V I$, end-diastolic volume index $\left(\mathrm{mL} / \mathrm{m}^{2}\right) ; S V I$, stroke volume index $\left(\mathrm{mL} / \mathrm{m}^{2}\right) ; P V R$, pulmonary vascular resistance (dynes $\left./ \mathrm{s} / \mathrm{cm}^{5}\right) ; E S P V R$, end-systolic pressure-volume relationship $(\mathrm{mm} H \mathrm{Hg} / \mathrm{mL}) ; E D P V R$, end-diastolic pressure-volume relationship $(\mathrm{mm} \mathrm{Hg} / \mathrm{mL}) ; d p / d t_{\text {max }}$ maximum rate of change of ventricular pressure $(\mathrm{mm} \mathrm{Hg} / \mathrm{s}) ; d p / d t_{\text {minr }}$ minimum rate of change of ventricular pressure $(\mathrm{mm} \mathrm{Hg} / \mathrm{s}) ; P R S W I$, preload recruitable stroke work index $\left(\mathrm{mm} \mathrm{Hg} / \mathrm{m}^{2}\right)$; Tau, relaxation time constant (ms).

dard deviation) ischemic time for the transplants was 179.8 (42.3) minutes. Recipient separation from cardiopulmonary bypass was normally performed on infusions of dopamine at 2 to $5 \mu \mathrm{g} / \mathrm{kg} / \mathrm{min}$ and isoprenaline at 0.005 to $0.01 \mu \mathrm{g} / \mathrm{kg} / \mathrm{min}$. All recipients had a pulmonary artery flotation catheter. RV dysfunction was predefined on the basis of the postoperative support instituted by an independent team of clinicians. It was diagnosed if all the following conditions were satisfied: right atrial pressure greater than 15 $\mathrm{mm} \mathrm{Hg}$, cardiac index less than $2.5 \mathrm{~L} / \mathrm{min} / \mathrm{m}^{2}$, wedge pressure less than $10 \mathrm{~mm} \mathrm{Hg}$, urine output less than $1 \mathrm{~mL} / \mathrm{kg} / \mathrm{h}$, and the need for special therapies ( $\geq 1$ of the following: intra-aortic balloon pulsation, pulmonary vasodilators, $\geq 3$ inotropes). Global graft dysfunction was diagnosed in the presence of borderline hemodynamics (cardiac index $<2.5 \mathrm{~L} / \mathrm{min} / \mathrm{m}^{2}$, wedge pressure $>15 \mathrm{~mm} \mathrm{Hg}$ ) and the need for special therapies as defined above.

\section{Pressure-Volume Loops Acquisition}

Load-independent indices were measured by a technique described in detail elsewhere. ${ }^{10}$ All studies were performed with patients under general anesthesia after donor optimization and before the institution of cardiopulmonary bypass in the CABG and domino groups. Because of time and logistical constraints a recipient study was only possible in 6 heart recipients, all of whom were recipients of brain-dead donors.

Cardiac output in brain-dead and domino donors was measured by thermodilution, whereas in controls a flow probe was applied around the pulmonary artery. For pressure-volume loops a $7 \mathrm{~F}$ catheter with an incorporated solid-state pressure transducer (Millar Instruments Inc, Houston, Tex) was inserted through a small sheath in the RV infundibulum. Pressure-volume loops were recorded at steady state, during parallel conductance determination, and during preload variation, achieved by transient inferior caval snaring over at least 5 consecutive cardiac cycles. All results were averaged from at least 2 measurements. The conductance signal was generated and processed in a Sigma-5 DF unit (Leycom, Leiden, The Netherlands). Parallel conductance was calculated from the intersection of end-systolic and end-diastolic points after injection of $7 \mathrm{~mL}$ of $10 \%$ saline at steady-state conditions (apnea). All volume measurements were corrected for the gain constant $\alpha$ calculated from the thermodilution or flow probe cardiac output. End diastole was defined by the $\mathrm{R}$ wave of the electrocardiogram, and end systole was defined by the maximum pressure/volume for each cardiac cycle. Data were analyzed off-line to obtain systolic and diastolic indices and the maximal $\left(\mathrm{dp} / \mathrm{dt}_{\max }\right)$ and minimal $\left(\mathrm{dp} / \mathrm{dt}_{\text {min }}\right)$ rate of ventricular pressure change. End-systolic pressurevolume relationships (ESPVR) and end-diastolic pressure-volume relationship (EDPVR) pressure-volume relationships were produced by linear regression of consecutive points in families of pressure-volume loops obtained during caval occlusion. The slopes of these relationships are presented and expressed in millimeters of mercury per milliliter. The time constant of pressure decay (Tau), describing early active relaxation, was derived by the half-pressure method. Cardiac output, end-diastolic volume, stroke volume, and preload recruitable stroke work were indexed by body surface area.

Contractile reserve was assessed using dopamine, the most common inotrope in donor management in the United Kingdom, infused at $5 \mu \mathrm{g} / \mathrm{kg} / \mathrm{min}$ over 7 minutes. Testing was done in usable donors after optimization, infusing dopamine over and above any preexisting inotropic load. This protocol was not instituted in 2 brain-dead donors and 1 domino because of time constraints. The stress protocol was not performed in the historical CABG-control group either.

\section{Statistics}

Because pressure-volume loop indices are typically normally distributed, parametric statistical methods were used. Results are 
TABLE 2. Cardiac parameters in donor hearts turned down on functional grounds $(n=5)$ and in organs with posttransplant allograft dysfunction $(n=10)$

\begin{tabular}{|c|c|c|c|c|c|c|}
\hline & $\begin{array}{l}\text { Brain-dead poor } \\
\text { function }(n=5)\end{array}$ & $\begin{array}{l}\text { Brain-dead good } \\
\text { function }(n=23)\end{array}$ & $P$ & $\begin{array}{c}\text { Posttransplant } \\
\text { dysfunction }(n=10)\end{array}$ & $\begin{array}{c}\text { No posttransplant } \\
\text { dysfunction }(\mathrm{n}=9)\end{array}$ & $P$ \\
\hline HR & $110(28)$ & $95(14)$ & .08 & $95(18)$ & $95(13)$ & .98 \\
\hline $\mathrm{Cl}$ & $3.1(1.1)$ & $3.3(0.6)$ & .68 & $3.7(0.7)$ & $3.1(0.4)$ & .03 \\
\hline $\mathrm{EF}$ & $43.4(14.8)$ & $42.2(11.4)$ & .84 & $40.8(14.8)$ & $42.9(7.9)$ & .69 \\
\hline EDVI & $81.8(48.4)$ & $89.6(35.9)$ & .69 & $114.4(40.4)$ & $77.2(17.2)$ & .02 \\
\hline SVI & $30.6(12.5)$ & $34.8(6.9)$ & .30 & $37.3(8.1)$ & $32.6(5.4)$ & .12 \\
\hline PVR & $113(54.4)$ & $87.6(26.8)$ & .13 & $97.8(32.3)$ & $85.3(27.7)$ & .37 \\
\hline ESPVR & $0.65(0.75)$ & $0.29(0.13)$ & .03 & $0.31(0.16)$ & $0.27(0.11)$ & .61 \\
\hline EDPVR & $0.034(0.04)$ & $0.078(0.08)$ & .15 & $0.068(0.06)$ & $0.047(0.05)$ & .15 \\
\hline $\mathrm{dp} / \mathrm{dt}_{\max }$ & $297(55)$ & $290(89)$ & .87 & $326(78)$ & $255(78)$ & .06 \\
\hline $\mathrm{dp} / \mathrm{dt}_{\min }{ }^{*}$ & $176(18)$ & 195 (148) & .78 & $255(208)$ & $140(46)$ & .12 \\
\hline PRSWI & $6.9(2.5)$ & $7.4(3.1)$ & .78 & $7.2(2.8)$ & $7.2(1.7)$ & .97 \\
\hline Tau & $31.4(12.9)$ & $58.8(27.6)$ & .04 & $56.4(34.3)$ & $57.5(27.3)$ & .94 \\
\hline $\mathrm{TPG}(\mathrm{mm} \mathrm{Hg})$ & - & - & & $9.3(5.1)$ & $9.0(2.1)$ & .90 \\
\hline Ischemic time (min) & - & - & & $193.6(50.3)$ & $181.7(27.4)$ & .53 \\
\hline
\end{tabular}

Data shown as mean (standard deviation). *Shown as absolute (positive) values. $H R$, heart rate (beats $/ \mathrm{min}) ; \mathrm{Cl}$, cardiac index (L/min $\left./ \mathrm{m}^{2}\right) ; E F$, ejection fraction (\%); EDVI, end-diastolic volume index $\left(\mathrm{mL} / \mathrm{m}^{2}\right) ; S V I$, stroke volume index $\left(\mathrm{mL} / \mathrm{m}^{2}\right) ; P V R$, pulmonary vascular resistance $\left(\mathrm{dynes} / \mathrm{s} / \mathrm{cm}{ }^{5}\right) ; E S P V R$, end-systolic pressure-volume relationship $(\mathrm{mm} \mathrm{Hg} / \mathrm{mL}) ; E D P V R$, end-diastolic pressure-volume relationship $(\mathrm{mm} \mathrm{Hg} / \mathrm{mL}) ; d p / d t_{\text {max }}$ maximum rate of change of ventricular pressure $(\mathrm{mm} \mathrm{Hg} / \mathrm{s}) ; d p / d t_{\text {min, }}$ minimum rate of change of ventricular pressure $(\mathrm{mm} \mathrm{Hg} / \mathrm{s})$; $P R S W I$, preload recruitable stroke work index (mm $\left.\mathrm{Hg} / \mathrm{m}^{2}\right) ; T a u$, relaxation time constant (ms); $T P G$, transpulmonary gradient.

summarized as mean (standard deviation) in Tables 1 and 2, and mean with $95 \%$ confidence intervals in Figures 1 to 3 . We used 1-way analysis of variance for comparisons between 2 or more independent groups. Where analysis of variance was significant we compared pairs of groups, adjusting for multiple comparisons with the Bonferroni correction. Outcome measurements from pre- to postdopamine and pre- to posttransplantation were compared using paired Student $t$ tests. Because this study is exploratory and all cardiac indices measured are important, each variable was assessed independently and no further adjustments for multiple comparison tests were made.

\section{Results}

Data are summarized in Tables 1 and 2 and Figures 2 and 3.

\section{Brain-Dead Donors, Domino Donors, and Coronary Artery Bypass Graft Surgery Group}

Brain-dead donors had a higher mean cardiac index than the CABG group; the ejection fraction was lower, but the stroke volume and heart rate were higher (Table 1, Figure 2, A). However, when volumetric parameters derived with the conductance catheter were included, donor hearts were significantly more dilated (end-diastolic volume index [EDVI] $89.6 \mathrm{~mL} / \mathrm{m}^{2}$ in brain-dead donors compared with 55.9 $\mathrm{mL} / \mathrm{m}^{2}$ in CABG group, $P=.02$ ). ESPVR was also significantly lower in brain-dead donors, reflecting a reduced contractile state. Tau, an index of isovolumic relaxation, was lower in brain-dead donors than in the CABG group (58.8 vs $87.5 \mathrm{~ms}, P=.06$ ). EDPVR describes late diastole and was elevated in brain-dead donors, meaning increased chamber stiffness, but the parameter had a large variability. The 5 domino hearts faced a higher pulmonary vascular resistance before retrieval and had a higher resting rate than cadaveric organs. Mean load-dependent indices were increased compared with the CABG group: stroke volume index, 23\%; dp/dt $\mathrm{dmax}_{\max }, 55 \%$; $\mathrm{dp} / \mathrm{dt}_{\min }, 179 \%$; and preload recruitable stroke work index, 28\%. Mean load-independent parameters showed a 20\% reduction in ESPVR compared with the CABG group, a mean EDVI greater by $56 \%$, and reduced early and late measures of diastole (Tau 36\% lower and EDPVR 64\% higher than average values in the CABG group).

\section{Contractile Reserve in Brain-Dead Donors}

After dopamine stimulation the cardiac index increased in brain-dead donors through higher heart rate and stroke volume, leading to a better preload recruitable stroke work index (Table 1, Figure 3). The ventricular chamber was more dilated, but the contractile indices ESPVR, EDPVR, and Tau were not improved.

\section{Usable Versus Unused Hearts from Brain-Dead Donors}

With the exception of Tau, none of the parameters studied were significantly different between these 2 groups of patients (Table 2). ESPVR showed marked variability in hearts with poor function (see "Discussion"). Unused hearts had a trend toward lower EDPVR. 

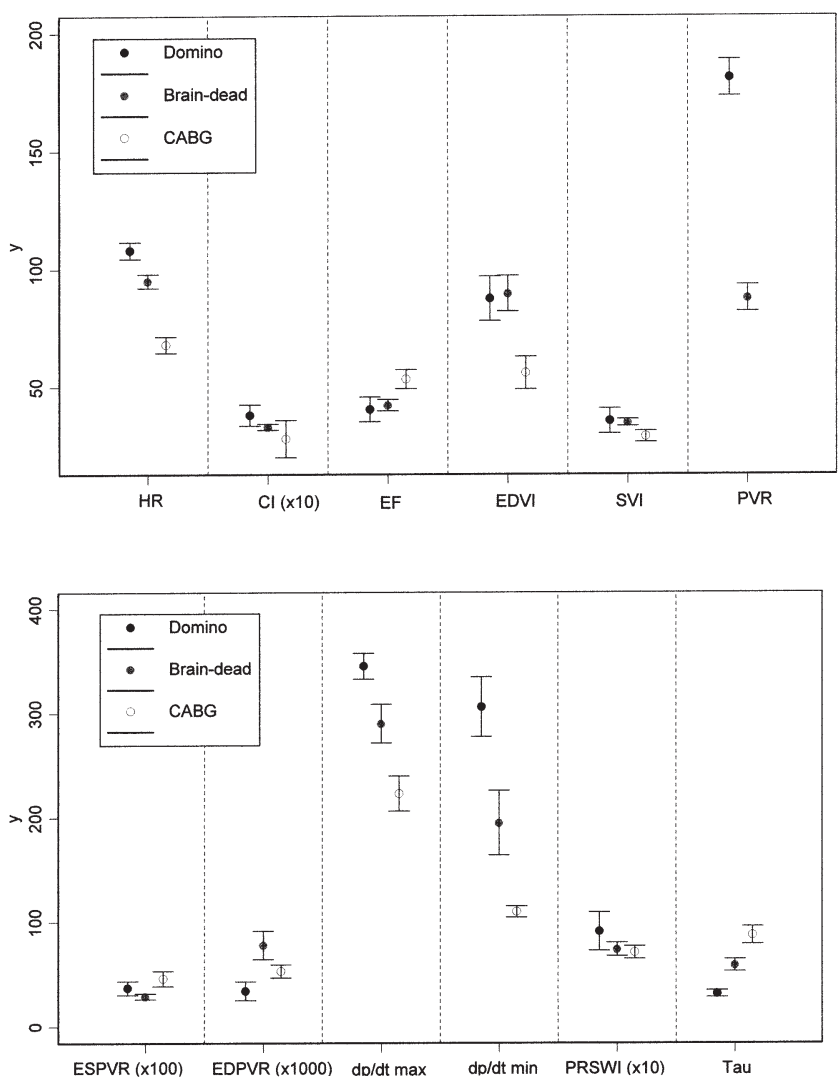

Figure 2. Mean and $95 \%$ confidence intervals for cardiac parameters in brain-dead donor optimized hearts, domino donors, and CABG patients. For abbreviations and units of measurement see Table 1.

\section{Donor Organ Dysfunction}

Table 2 shows donor studies from the 19 brain-dead donors, classified according to allograft dysfunction in the recipient. Before explantation, hearts that went on to develop posttransplant dysfunction were significantly more dilated than organs not associated with this complication (EDVI 114.4 vs $77.2 \mathrm{~mL} / \mathrm{m}^{2}, P=.02$ ). There were no other important findings in this comparison, so the subdivision of right versus global allograft failure was not investigated further.

\section{Discussion}

To our knowledge this is the first study in human donors describing load-independent parameters of RV contractility. Furthermore, the donors were treated and stabilized in accordance with the principles of the Crystal City consensus report. ${ }^{4}$ Major abnormalities of RV systolic and diastolic dysfunction were demonstrated in brain-dead and domino donors compared with the CABG group. Load-independent measurements require open surgery; thus, a pragmatic approach to obtaining comparison data was taken. The com-
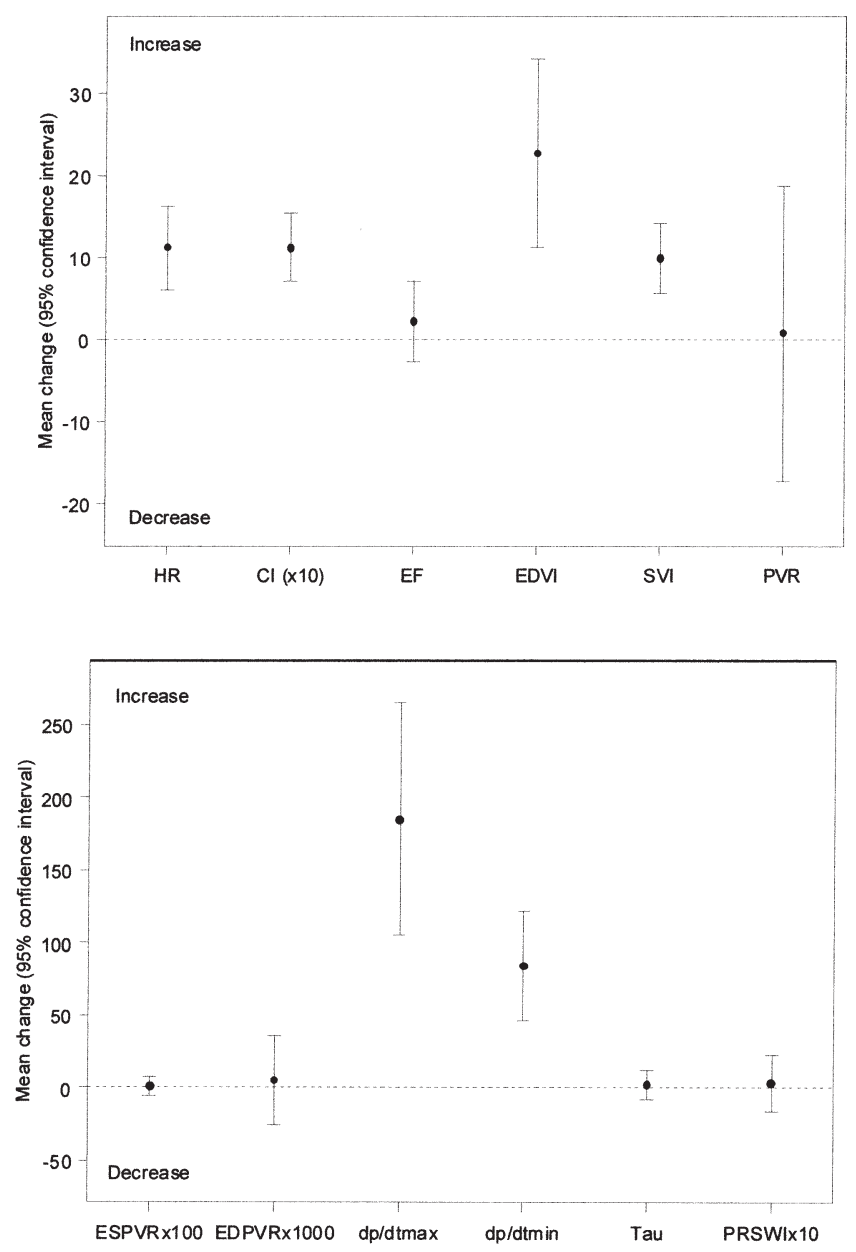

Figure 3. Mean change of cardiac parameters in usable braindead donors subjected to dopamine stimulation ( $n=21$ ). For abbreviations and units of measurement see Table 1.

parison groups are less then ideal because cystic fibrosis ${ }^{11}$ and ischemic heart disease ${ }^{12}$ both affect RV performance. Strictly speaking, we compare 3 groups with different pathologies. However, the brain-dead donors had preload and afterload optimization based on pulmonary catheter data, so the changes described are likely to reflect the true contractile state.

\section{Brain-Dead Donors, Domino Donors, and Coronary Artery Bypass Graft Surgery Group}

Systole. Both the domino and brain-dead donors had impaired RV contractility, although likely for different reasons. Loss and even reversal of the normal force-frequency relationship ${ }^{13}$ may be a manifestation of the chronic RV dysfunction seen in cystic fibrosis, which can be demonstrated subclinically. ${ }^{11}$ All of the domino donors were symptomatic from end-stage lung disease, a situation asso- 
ciated with progressive pulmonary hypertension and overt $\mathrm{RV}$ failure. This is compatible with the findings of an increased intraoperative pulmonary vascular resistance, RV dilatation, and reduced contractility. A higher ejection phase index $\mathrm{dp} / \mathrm{dt}_{\max }$ seen in domino donors is in keeping with the known adaptation imposed by chronic pulmonary hypertension and should not be interpreted as "superior" systolic function. ${ }^{11,14}$ We lacked pulmonary vascular resistance data in the $\mathrm{CABG}$ group, so this comparison with controls was not possible.

The mechanisms for reduced RV contractility seen in brain-dead donors may be more complex. The process of brain death itself is associated with marked ventricular dysfunction, ${ }^{1,6-9}$ there are multiple potential secondary effects of resuscitation in the donor, and there is a variably prolonged period of ischemia between harvest and implantation. In animal experiments pulmonary vascular resistance after brain death is an unresolved issue, partly because of various study methods used. Bittner and colleagues ${ }^{6}$ showed that brain death leads to decreased afterload, with no change in the transvascular pulmonary efficiency of the RV, whereas Szabo and colleagues ${ }^{8}$ did not replicate these findings in the presence of a tighter control of loading conditions. It is therefore possible that the reduced ESPVR seen in braindead donors in this study represents RV adaptation to decreased afterload. This would be an illustration of the Anrepp effect (homeometric autoregulation), which is also at work in the left ventricle of brain-dead animals exhibiting decreased systemic vascular resistance, ${ }^{9}$ and in newborn lambs whose RV is subjected to an acute increase in afterload. ${ }^{15}$ Even if ejection fraction and stroke volume index are comparable in our 3 groups, the impact of brain death on $\mathrm{RV}$ function is most apparent when EDVI is observed. Brain-dead donors with an average age of 39.2 years have end-diastolic volumes higher than in domino donors with chronic pulmonary hypertension and significantly higher than in older patients in the CABG group. More research is needed to determine beyond what level the RV dilatation after brain death is maladaptive and favors organ failure.

Diastole. The difference in isovolumic relaxation between the 3 groups, described by $\mathrm{dp} / \mathrm{dt}_{\min }$, is difficult to interpret given their markedly different loading conditions. Our findings are comparable to other published results correlating $\mathrm{dp} / \mathrm{dt}_{\min }$ and contractile indices in lambs ${ }^{16}$ and in humans with ischemic heart disease. ${ }^{17}$ Although diastolic compliance, as measured by EDPVR, was not significantly different between the 2 groups, $\mathrm{dp} / \mathrm{dt}_{\min }$ was higher and Tau was shorter in donor hearts compared with controls. This pattern of diastolic response is in keeping with the known load and heart-rate dependence of the relaxation indices, ${ }^{16}$ and is likely therefore to represent secondary adaptive phenomena. Primary abnormalities of diastolic performance do not seem to provide an explanation for the abnormal donor physiology described in our patients. It must be emphasized that the open chest-open pericardium nature of our investigations mitigates against demonstrating more subtle disturbances, or ventricular-ventricular interactions that could be manifest with the chest closed.

\section{Contractile Reserve in Brain-Dead Donors}

Inotropic stimulation increased cardiac output as a product of higher heart rate and increased stroke volume (Figure 3). The pattern of response to dopamine was highly abnormal, however. There was no change in ESPVR, and the increased stroke volume was achieved not by a reduction in endsystolic volume, but by a paradoxic increase in RV enddiastolic volume. This is a manifestation of pump failure, with the RV dilating in response to the increased preload, presumably from increased left heart output. Again, the open chest preparation precludes further analysis, but our data support the tenuous nature of cardiac function in transplanted hearts from brain-dead donors. It is easy to see how modest changes in RV preload as a result of volume transfusion, or even as paradoxic result of inotropic stimulation, could lead to RV failure and subsequent allograft dysfunction. Indeed, we previously showed that isolated right heart dilatation may have adverse effects on left ventricular contractile efficiency, which is amplified when the pericardium is closed. ${ }^{18}$ The relationship between inotropic usage and donor organ outcomes was analyzed elsewhere, using both thermodilution ${ }^{19}$ and the conductance catheter.$^{20}$ Until more research is available in donor-recipient risk matching, clinicians should be cautious in using cadaveric donor hearts with high doses of inotropes.

\section{Usable Versus Unused Hearts from Brain-Dead Donors}

"Usability" was defined in terms of the extended criteria currently operating at Papworth. ${ }^{19}$ The unused hearts were no different, in terms of objective measurements of RV contractility, compared with the hearts that were transplanted. The number of unusable hearts was small, so it is impossible to comment on the potential of the conductance catheter to expand the donor pool. Our data suggest that further cross-sectional studies should be performed to assess the utility of this technique in selecting viable hearts. It is conceivable that, similar to highenergy phosphates when used as a descriptor of function, ${ }^{21}$ abnormal donor hearts already fail the "usability" test of a new technology on conventional criteria or simply reflect the fluid or inotropic load. For example, 1 of the unused donors was receiving dopamine, noradrenaline, and adrenaline (in doses of 8, 0.07, and $0.01 \mu \mathrm{g}$. $\mathrm{kg} \cdot \mathrm{min}$, respectively) and exhibited a markedly outlying ESPVR at $1.99 \mathrm{~mm} \mathrm{Hg} / \mathrm{mL}$, also accounting for the high variability of this parameter. 


\section{Donor Organ Dysfunction}

This complication is notoriously multifactorial, and, although it was not an objective of the study, we have been unable to identify a predictive contractile index. Variables associated with donor organ failure can be reasonably classified as related to the donor, operation, and recipient. An example in each category would be brain death, long ischemic time, and pulmonary hypertension, respectively, each of these being implicated in posttransplant function. Despite the cumbersome technology involved, another group used the conductance catheter in the left ventricle of 14 human donors and showed that ventriculoarterial coupling in the systemic circulation is a predictor of posttransplant performance, ${ }^{22}$ in keeping with subsequent experimental work by Szabo and colleagues. ${ }^{8,9}$ It is remarkable that in this study hearts with posttransplant dysfunction were significantly more dilated at the baseline, a possible early marker of failure (Table 2). The fact that the EDVI in hearts turned down on functional grounds (by conventional criteria) was not particularly elevated makes EDVI a questionable marker of organ quality (Table 2). It seems that other factors, some still unknown, related to ischemic time, reperfusion, and recipient came into play. Of these we only compared ischemic time and transpulmonary gradient between the 2 groups, with no significant difference (Table 2). It is difficult to separate the true effect of transplantation because cardiopulmonary bypass per se transiently impairs systolic and diastolic pressure-volume indices. ${ }^{10}$ In regard to posttransplant adaptation, in a separate limited analysis we previously showed that $\mathrm{dp} /$ $\mathrm{dt}_{\max }$ is able to increase in the recipient despite implantation in a circulation with a much higher pulmonary vascular resistance. ${ }^{21}$ Less invasive, load-independent studies of contractility, now possible with tissue Doppler technology, ${ }^{23}$ may permit these issues to be studied further in larger patient groups.

\section{Limitations}

This was a pragmatic exploratory study of consecutive donor hearts in humans, which necessarily lacks the controls of an experimental preparation. Thus, the effects, type, and time interval from brain death were all variable. Although this work provides unique insights into RV contractile responses, it also has some deficiencies. Because of logistic constraints we could not obtain data on the left ventricle and septum. Measurements with the pericardium closed and ventriculoarterial coupling data are also lacking. Nonetheless, our data clearly demonstrate abnormal RV physiology and inotropic responses in donor hearts compared with controls. The use of data from patients with ischemic heart disease who undergo $\mathrm{CABG}$, although not ideal, was also based on pragmatism. It is clearly unethical to obtain com- parative open-chest conductance, catheter-derived data concerning RV function in entirely healthy subjects. It should be emphasized that although the control patients were hemodynamically stable with no overt ischemia at the time of study, we cannot exclude some intrinsic abnormalities of function in this group. However, any dysfunction would likely obviate differences by comparison with donor hearts, and therefore do not undermine our conclusions. Finally, the number of patients studied represent one of the largest subjected to such detailed hemodynamic assessment, but cannot be expected to provide information regarding the utility of these measurements in patient selection. Larger cross-sectional studies using conductance catheter-derived criteria would be required to answer such questions. A bigger study, specifically focused on posttransplant dysfunction, would be able to account better for the multiple competing factors leading to this complication. In addition, for many of the comparisons there was sufficient power to identify only major differences; more moderate effects may become evident in larger studies.

\section{Conclusion}

This study describes the physiologic changes occurring in donor hearts with and without brain death. Marked abnormalities of RV performance exist in both brain-dead and domino donors, which have implications for global functional performance and treatment after transplantation. In particular, the abnormal responses to increased preload that occur during inotropic stimulation may have important implications for fluid and pressor management in patients receiving transplants from brain-dead donors.

Susan Charman provided advice on the statistical analysis in the early stages of this study. We thank the surgeons at Papworth and the regional transplant coordinators for making this study possible.

\section{References}

1. Bittner HB, Chen EP, Biswas SS, Van Trigt P, Davis RD. Right ventricular dysfunction after cardiac transplantation: primarily related to status of donor heart. Ann Thorac Surg. 1999;68:1605-11.

2. Wheeldon DR, Potter CD, Oduro A, Wallwork J, Large SR. Transforming the 'unacceptable' donor: outcomes from the adoption of a standardized donor management technique. J Heart Lung Transplant. 1995; 14:734-42.

3. Hosenpud JD, Bennett LE, Keck BM, Fiol B, Boucek MM, Novick RJ The Registry of the International Society for Heart and Lung Transplantation: fifteenth official report-1998. J Heart Lung Transplant. 1998; 17:656-68.

4. Zaroff JG, Rosengard BR, Armstrong WF, et al. Consensus conference report: maximizing use of organs recovered from the cadaver donor: cardiac recommendations. Circulation. 2002;106:836-41.

5. Levine RA, Gibson TC, Aretz T, et al. Echocardiographic measurements of right ventricular volume. Circulation. 1984;69:497-505.

6. Bittner HB, Kendall SWH, Chen EP, Craig D, Van Trigt P. The effects of brain death on cardiopulmonary hemodynamics and pulmonary blood flow characteristics. Chest. 1995;108:1358-63. 
7. Kendall SWH, Bittner HB, Peterseim DS, Campbell KA, Van Trigt P. Right ventricular function in the donor heart. Eur J Cardiothorac Surg. 1997;11:609-15.

8. Szabo G, Sebening C, Hagl C, Tochtermann U, Vahl CF, Hagl S. Right ventricular function after brain death: response to an increased afterload. Eur J Cardiothorac Surg. 1998;13:449-59.

9. Szabo G, Hackert T, Buhmann V, et al. Downregulation of myocardial contractility via intact ventriculo-arterial coupling in the brain dead organ donor. Eur J Cardiothorac Surg. 2001;20:170-6.

10. Brookes CI, White PA, Bishop AJ, Oldershaw PJ, Redington AN, Moat NE. Validation of a new intraoperative technique to evaluate load-independence indices of right ventricular performance in patients undergoing cardiac operations. J Thoracic Cardiovasc Surg. 1998; 116:468-76.

11. Ionescu AA, Ionescu AA, Payne N, Obieta-Fresnedo I, Fraser AG, Shale DJ. Subclinical right ventricular dysfunction in cystic fibrosis. A study using tissue Doppler echocardiography. Am J Respir Crit Care Med. 2001;163:1212-8.

12. Bishop A, White PA, Chaturvedi RR, Brookes CI, Redington AN, Oldershaw PJ. Resting right ventricular function in patients with coronary artery disease: pressure volume analysis using conductance catheters. Int J Cardiol. 1997;58:223-8.

13. Endoh M. Force-frequency relationship in intact mammalian ventricular myocardium: physiological and pathophysiological relevance. Eur J Pharmacol. 2004;500:73-86.

14. Leeuwenburgh BPJ, Helbing WA, Steendijk P, Schoof PH, Baan J. Biventricular systolic function in young lambs subject to chronic systemic right ventricular pressure overload. Am J Physiol Heart Circ Physiol. 2001;281:H2697-704.

15. De Vroomen M, Lopes Cardozo RH, Steendijk P, Van Bel F, Baan J. Improved contractile performance of right ventricle in response to increased RV afterload in newborn lamb. Am J Physiol Heart Circ Physiol. 2000;278:H100-5.

16. Leeuwenburgh BPJ, Steendijk P, Helbing WA, Baan J. Indexes of diastolic RV function: load dependence and changes after chronic RV pressure overload in lambs. Am J Physiol Heart Circ Physiol. 2002; 282:H1350-8.

17. De Hert SG, Gillebert TC, ten Broecke PW, Mertens E, Rodrigus IE, Moulijn AC. Contraction-relaxation coupling and impaired left ventricular performance in coronary surgery patients. Anesthesiology. 1999;90:748-57.

18. Brookes CI, Ravn H, White PA, Moeldrup U, Oldershaw PJ, Redington AN. Acute right ventricular dilatation in response to ischemia significantly impairs left ventricular systolic performance. Circulation. 1999;100:761-7.

19. Stoica SC, Satchithananda DK, Charman S, et al. Swan-Ganz catheter assessment of donor hearts: outcome of organs with borderline hemodynamics. J Heart Lung Transplant. 2002;21:615-22.

20. Stoica SC, Satchithananda DK, White PA, Parameshwar J, Redington AN, Large SR. Noradrenaline use in the human donor and relationship with load-independent right ventricular contractility. Transplantation. 2004;78:1193-7.

21. Stoica SC, Satchitanda DK, Atkinson C, et al. The energy metabolism in the right and left ventricles of human donor hearts across transplantation. Eur J Cardiothorac Surg. 2003;23:503-12.

22. Yokoyama Y, Gooper DK, Sasaki H, Snow TR, Akutsu T, Zuhdi N. Donor-heart evaluation by monitoring the left ventricular pressure-volume relationship: clinical observations. J Heart Lung Transplant. 1992:685-92.

23. Vogel M, Schmidt MR, Kristiansen SB, et al. Validation of myocardial acceleration during isovolumic contraction as a novel noninvasive index of right ventricular contractility. Circulation. 2002:105:1693-9.

Access to The Journal of Thoracic and Cardiovascular Surgery Online is reserved for print subscribers!

Full-text access to The Journal of Thoracic and Cardiovascular Surgery Online is available for all print subscribers. To activate your individual online subscription, please visit The Journal of Thoracic and Cardiovascular Surgery Online, point your browser to http://www.mosby.com/jtcvs, follow the prompts to activate your online access, and follow the instructions. To activate your account, you will need your subscriber account number, which you can find on your mailing label (note: the number of digits in your subscriber account number varies from 6 to 10). See the example below in which the subscriber account number has been circled:

\section{Sample mailing label}

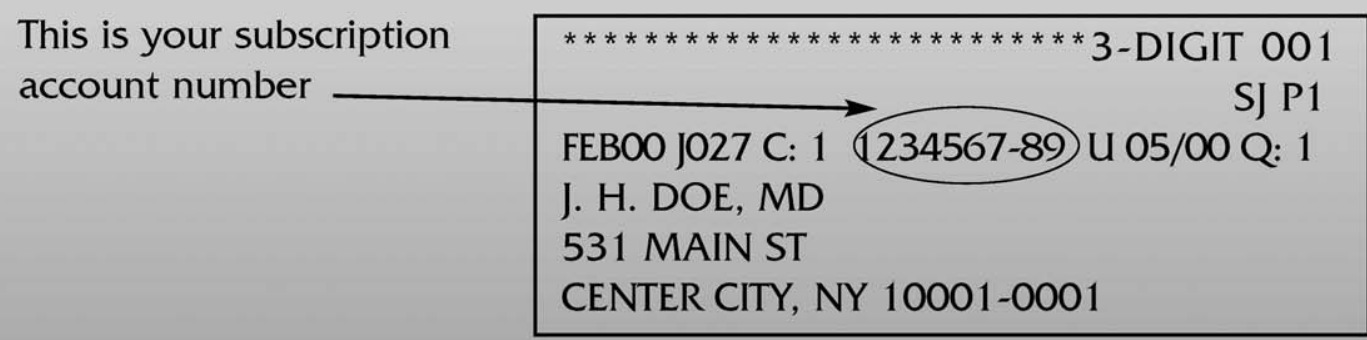

Personal subscriptions to The Journal of Thoracic and Cardiovascular Surgery Online are for individual use only and may not be transferred. Use of The Journal of Thoracic and Cardiovascular Surgery Online is subject to agreement to the terms and conditions as indicated online. 